\title{
L-arginine supplementation and resistance training promotes increase of maximum strength and protection from DNA damage in rats
}

\begin{abstract}
L-arginine (Arg) is a precursor of several substances with remarkable physiological functions, such as nitric oxide (NO) and the amino acid creatine. Arg supplementation has been associated with increased strength in high-intensity exercise. However, there is no clear evidence of association of supplementation with Resistance Training (RT) on their antioxidant and ergogenic effects, specifically on their genotoxic protection. Therefore, we evaluated the effect of supplementation of Arg associated with RT 8 weeks about gaining maximum strength and DNA damage in rats. Ten Wistar rats (220-270g, 90days old) were randomly divided into 3 groups: sedentary (SED, n=4), Resistance Training (RT, $n=2$ ) and Resistance Training + L-Arginine ( $R T+A r g, n=4)$. Trained rats were submitted to the protocol of RT in a squat apparatus adapted for rats (4 sets of 10-12 reps with 90 s interval, 4 times/week, $65-75 \%$ of One Maximum Repetition (1MR) for 8 weeks). The supplemented group received Arg $(500 \mathrm{mg} / \mathrm{kg})$ daily for 8 weeks. After 8 weeks, whole blood was collected from animals to perform the comet assay. It was used CASP software (CASPLabs $\left.{ }^{\circledR}\right)$ for quantification of DNA damage. To quantify the maximum strength the $1 \mathrm{MR}$ test was performed at baseline and after the RT protocol. For comparisons among groups it was performed Oneway ANOVA followed by post hoc test of Student-Newman-Keuls. For associations, it was used the Pearson correlation test. We considered the level of significance of $5 \%$.The RT was able to protect DNA damage in rats. However, the association with Arg supplementation was able to promote greater genotoxic protection, compared to sedentary rats. These results indicate remarkable ergogenic action and genotoxic protection of Arg supplementation in association with RT.
\end{abstract}

Volume I Issue 4 - 2014

\author{
Stefani GP, ${ }^{1,2}$ Nunes RB, I,2 Alves JP, I, 2 \\ Domenico MD, 1,3 Marmett B, ${ }^{1,2}$ Moller GB, ${ }^{1,2}$ \\ Dal Lago P, ${ }^{1,2}$ Rhoden CR ${ }^{1,3}$ \\ 'Federal University of Health Sciences of Porto Alegre \\ (UFCSPA), Brazil \\ 'Laboratory of Physiology, UFCSPA, Brazil \\ ${ }^{3}$ Laboratory of Oxidative Stress and Air Pollution, UFCSPA, \\ Brazil
}

Correspondence: Giuseppe Potrick Stefani, Laboratory of Physiology, Federal University of Health Sciences of Porto Alegre (UFCSPA), Sarmento Leite Street, 245, Porto Alegre, Rio Grande do Sul, Brazil,Tel 33038820, Fax 3303880I, Email gpotrick@gmail.com

Received: June 09, 2014 | Published: July 18, 2014

Keywords: arginine, resistance training, supplementation, exercise, DNA damage, genotoxicity, rats

Abbreviations 1MR, one maximum repetition; Arg, 1-arginine; cGMP, cyclic guanosine monophosphate; DNA, deoxyribonucleic acid; GTP, guanosine triphosphate; NO, nitric oxide; NOS, nitric oxide synthase; OTM, olive tail moment; RONS, reactive oxygen and nitrogen species; RT, resistance training; TM, tail moment

\section{Introduction}

The supplementation of L-arginine (Arg) has been showed to improve performance in high intensity and short duration exercises, such as weightlifting, ${ }^{1,2}$ possibly due to its vasodilating action. In this reaction mediated by the conversion of Arg to citrulline, the production of nitric oxide (NO) occurs by the enzymatic catalysis of nitric oxide synthase (NOS). The NO is a Reactive Oxygen and Nitrogen Specie (RONS), found in the form of molecular gas. The responsible enzyme to produce NO is NOS, which may be expressed constitutively in endothelial isoform (eNOS), neuronal (nNOS) and inducible form (iNOS). ${ }^{3}$ The decoupling of NOS constitutive forms lead to the overproduction of two oxidants in endothelium: the superoxide anion-radical $\left(\mathrm{O}_{2}-\bullet\right)$ and peroxynitrite (ONOO-). These both free radicals are associated with the development of endothelial disfunction. ${ }^{4}$

Under normal conditions, endothelium produces NO by Arg in the presence of oxygen catalyzed by eNOS. The NO diffuses into the adjacent smooth muscle, where it is modulated by guanylate cyclase. This enzyme has the function of converting guanosine triphosphate (GTP) into cyclic guanosine monophosphate (cGMP), thereby causing relaxation of vascular wall. ${ }^{5}$ In situations where it is established a dysfunction of vascular endothelium, production of $\mathrm{NO}$ occurs in the same manner, together with high concentrations of $\mathrm{O}_{2}$ -, which is caused by the decoupling of electrons in the reaction of eNOS. In this case, the $\mathrm{O}_{2} \bullet$ can be converted into hydrogen peroxide.

The NO may react with $\mathrm{O}_{2}-\bullet$ and form ONOO-, which is a highly cytotoxic compound. ${ }^{6}$ Free radicals have high reactivity to adjacent biomolecules. It is well established that reactive species leads to the impairment of important cellular structures such as lipid peroxidation (mainly in plasmatic membranes), damage in proteins (signaling proteins, enzymes and other proteins) and genomic damage (oxidation of nucleic acids).

The Resistance Training (RT) has been widely utilized by the general population as a very effective method in promoting gains of muscle strength, increase power performance in sports, preventing muscle lesions and increased quality of life. ${ }^{7}$ Despite of the scientific literature demonstrate benefits of Arg supplementation in exercised conditions, there are few evidence of associating of supplementation with RT on their ergogenic effects, as well as on genotoxic protection. For that reason, we evaluated the effect of supplementation of Arg associated with RT 8weeks about gaining maximum strength and DNA damage in rats.

\section{Methodology}

Ten Wistar rats (220-270g, 90days old) were randomly divided into 3 groups: Sedentary (SED, $n=4)$, Resistance Training (RT, $n=2)$ and Resistance Training + L-Arginine $(\mathrm{RT}+\mathrm{Arg}, \mathrm{n}=4)$. The animals were housed under standard conditions (food and water ad libitum, 
temperature between 22 and $24^{\circ} \mathrm{C}$, light - dark cycle of 12 hours). This study was approved by CEUA/UFCSPA, under the protocol number $114 / 13$.

\section{Resistance training protocol}

Trained rats were submitted to a RT protocol in a squat apparatus adapted for rats $^{8,9}$ (4 sets of 10-12 reps with 90s interval, 4times/ week, $65-75 \%$ of One Maximum Repetition (1MR) for 8 weeks). An electrical stimulus $(4-5 \mathrm{~mA}, 0.3 \mathrm{~seconds}$ long, with a 3 second interval between each repetition ${ }^{10}$ was applied in the rat's tail using a surface electrode, in order to provoke the extension movement of the lower limbs of the rat.

To quantify the maximum strength, it was performed the $1 \mathrm{MR}$ test at baseline and after the RT protocol. To determine the maximum lifted load in one repetition, the One Maximum Repetition (1MR) was utilized. From the obtained value, the load percentage required to perform the training protocol were determined. In response to training, it is expected strength gains along the training, making the realization of retests every two weeks necessary, in order to adjust the training load.

\section{L-Arginine supplementation}

It was utilized L-Arginine (presentation form: powder, with purity of $99.9 \%$, Sigma-Aldrich $\AA$, Brazil). The supplementation was given by gavage solution, as this resembles human oral consumption and ensures that the desired dosage is achieved. The supplemented group received Arg $(500 \mathrm{mg} / \mathrm{kg})$ daily for 8 weeks. ${ }^{11}$ The animals received the supplement every day before training for the entire period of the protocol (including thedays on which they did not train).

\section{Comet assay (alkaline version)}

After 8weeks, whole blood was collected from animals to perform the comet assay. The alkaline Comet Assay in peripheral blood was performed as described in the literature ${ }^{12,13}$ with minor changes. It was used $20 \mu \mathrm{L}$ of whole peripheral blood embedded in $90 \mu \mathrm{L}$ of $0.75 \%$ low-melting point agarose at $37^{\circ} \mathrm{C}$. This mixture was placed into a slide previously coated with $1.5 \%$ of normal melting point agarose processed at $60^{\circ} \mathrm{C}$. A cover glass was placed on top and the agar allowed to set at $4^{\circ} \mathrm{C}$ and, after gel solidifying, the cover glass were removed. Then, the slides were immersed in iced-cold lysis solution (2.5 M NaCl, $100 \mathrm{mM}$ EDTA and $10 \mathrm{mM}$ Tris, $\mathrm{pH} 10.0$; containing freshly added $1 \%(\mathrm{v} / \mathrm{v})$ Triton X-100 and $10 \%$ (v/v) dimethylsulfoxide (DMSO) at $4^{\circ} \mathrm{C}$ in dark for a minimum of $1 \mathrm{~h}$. Afterwards, to allow DNA unwinding, slides were incubated in a freshly made alkaline electrophoresis buffer $(0.3 \mathrm{MNaOH}$ and $1 \mathrm{mM}$ EDTA; $\mathrm{pH}>13)$ at $4{ }^{\circ} \mathrm{C}$ for $5 \mathrm{~min}$ in a horizontal electrophoresis box. The alkaline electrophoresis was carried out for $15 \mathrm{~min}$ at $25 \mathrm{~V}$ and $300 \mathrm{~mA}$. Every step was carried in dark. After electrophoresis, slides were washed threetimes in a neutralization buffer $(0.4 \mathrm{M}$ Tris; $\mathrm{pH} 7.5)$ for $5 \mathrm{~min}$, rinsed twice in distilled water, and left to dry overnight at room temperature. Then, the slides were fixed for $10 \mathrm{~min}$ in trichloroacetic acid $15 \% \mathrm{w} / \mathrm{v}$, zinc sulfate $5 \% \mathrm{w} / \mathrm{v}$, glycerol $5 \% \mathrm{v} / \mathrm{v}$, rinsed threetimes in distilled water, and dried for $2 \mathrm{~h}$ at $37^{\circ} \mathrm{C}$. Finally, the slides were stained with silver nitrate as previously described by Nadin et al., ${ }^{14}$

For DNA damage quantification, it was used CASP software (CASPLabs $\left.{ }^{\circledR}\right) .{ }^{15}$ The software can detect three different types of markers of genotoxic damage, such as percentage of tail DNA, tail moment (represents the distance of DNA migration from the head of the comet) and olive tail moment (represents the product of the tail length and the fraction of DNA in the tail). For image analysis it was scored 100 comets per slide.

\section{Statistical analysis}

The results are expressed in mean $\pm \mathrm{SD}$. For comparisons among groups it was performed One-way ANOVA followed by post hoc test of Student-Newman-Keuls. For associations, it was used the Pearson correlation test. We considered the level of significance of $5 \%$.

\section{Results}

All of the groups showed no differences at the baseline of resistance training protocol $(\mathrm{P}>0.05)$. After 8 weeks of training, it was observed higher maximum strength in the trained groups, when compared to the sedentary group $(\mathrm{P}<0.05)$. However, the $\mathrm{RT}+\mathrm{Arg}$ group showed greater maximum strength than the other groups $(\mathrm{P}<0.05)$ (Figure 1).

Regarding damage to DNA, \% Tail DNA was lower in RT + Arg, compared with RT and SED groups $(\mathrm{P}<0.05)$ (Figure 2$)$ as well as in other genotoxic markers: Tail Moment $(\mathrm{TM})(\mathrm{P}<0.05)$ (Figure 3$)$ and Olive Tail Moment (OTM) $(\mathrm{P}<0.05)$ (Figure 4).

It was observed a strong inversely proportional correlation between different markers of DNA damage with maximum strength. Percentage of Tail DNA with 1MR $(r=-0.9719, \mathrm{P}<0.05)$, TM with $1 \mathrm{MR}(r=-0.9046, \mathrm{P}<0.05)$ and OTM with $1 \mathrm{MR}(r=-0.9079, \mathrm{P}<0.05)$.

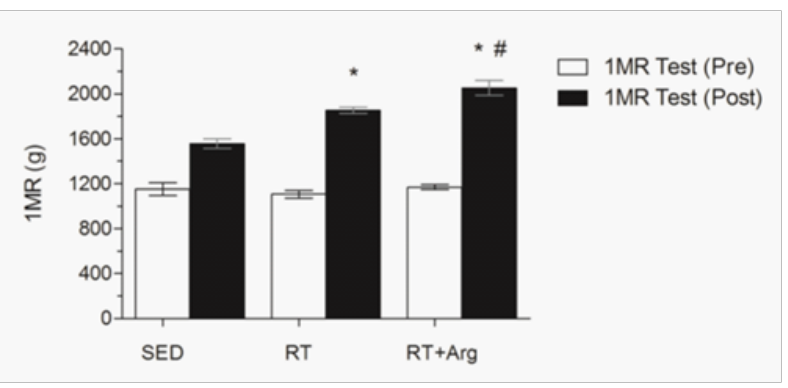

Figure I Maximum strength pre and post 8 weeks of study protocol.

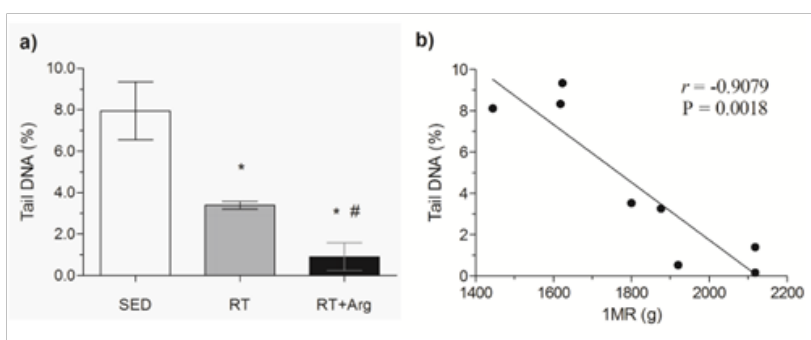

Figure 2 DNA damage in lymphocytes measured by alkaline comet assay. A) $\%$ Tail DNA; B) Pearson correlation test between \% Tail DNA and the final test of IMR.

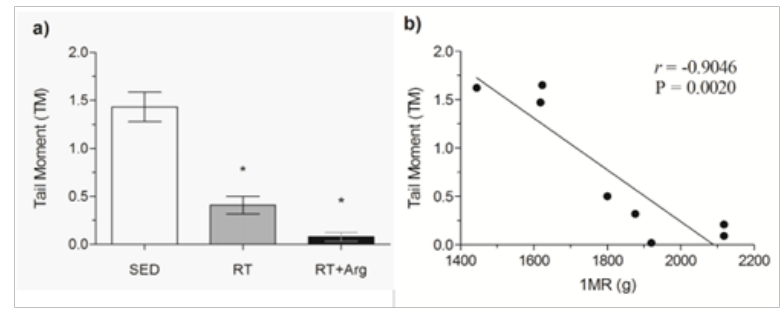

Figure 3 DNA damage in lymphocytes measured by alkaline comet assay. A) Tail Moment (TM); B) Pearson correlation test between Tail Moment (TM) and the final test of IMR. 


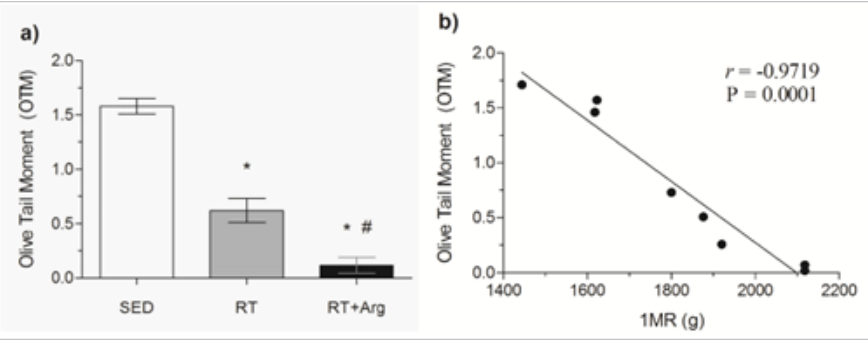

Figure 4 DNA damage in lymphocytes measured by alkaline comet assay.A) Olive Tail Moment (OTM); B) Pearson correlation test between Olive Tail Moment (OTM) and the final test of IMR.

\section{Conclusion}

The RT was able to protect DNA damage in rats. However, the association with Arg supplementation was able to promote greater genotoxic protection, compared to sedentary rats. Also, the association of RT with Arg supplementation increase maximum strength after the training protocol. These results indicate remarkable ergogenic action and genotoxic protection of Arg supplementation in association with RT.

\section{Acknowledgments}

This work was supported by grants from CAPES and CNPq, Brasilia, Brazil.

\section{Conflict of interest}

Author declares that there is no conflict of interest.

\section{References}

1. Angeli G, de Barros TL, de Barros DFL, Investigation of the effects of ora supplementation of arginine in the increase of muscular strength and mass. Rev Bras Med Esporte. 2007;139(2):129-132.

2. Santos RS, Pacheco MTT, Martins RABL, et al. Study of the effect of oral administration of L-arginine on muscular performance in healthy volunteers: An isokinetic study. Isokinetics and Exercise Science. 2002;10(3):153-158.
3. Smith TW, Balligand JL, Kaye DM, et al. The role of the NO pathway in the control of cardiac function. J Card Fail. 1996;2(4 Suppl):S141-S147.

4. Kalinowski L, Dobrucki IT, Malinski T. Race-specific differences in endothelial function: predisposition of African Americans to vascular diseases. Circulation. 2004;109(21):2511-2517.

5. Malinski T. Understanding nitric oxide physiology in the heart: a nanomedical approach. Am J Cardiol. 2005;96(7B):13i-24i.

6. Brovkovych V, Dobrucki LW, Brovkovych S, et al. Nitric oxide release from normal and dysfunctional endothelium. J Physiol Pharmacol. 1999;50(4):575-586.

7. Roig M, O'Brien K, Kirk G, et al. The effects of eccentric versus concentric resistance training on muscle strength and mass in healthy adults: a systematic review with meta-analysis. $\mathrm{Br} J$ Sports $\mathrm{Med}$. 2009;43(8):556-568.

8. Barauna VG, Batista ML, Costa Rosa LF, et al. Cardiovascular adaptations in rats submitted to a resistance-training model. Clin Exp Pharmacol Physiol. 2005;32(4):249-254.

9. Krisan AD, Collins DE, Crain AM, et al. Resistance training enhances components of the insulin signaling cascade in normal and high-fat-fed rodent skeletal muscle. J Appl Physiol. 2004;96(5):1691-1700.

10. Stefani GP, Nunes RB, Dornelles AZ, et al. Effects of creatine supplementation associated with resistance training on oxidative stress in different tissues of rats. J Int Soc Sports Nutr. 2014;11(1):11.

11. Krauss H, Bogdanski P, Sosnowski P, et al. Influence of short-term L-arginine supplementation on carbohydrate balance in rats with ischemiareperfusion syndrome. Pharmacol Rep. 2012;64(3):635-642.

12. Singh NP, McCoy MT, Tice RR, et al. A simple technique for quantitation of low levels of DNA damage in individual cells. Exp Cell Res. 1988;175(1):184-191.

13. Tice RR, Agurell E, Anderson D, et al. Single cell gel/comet assay: guidelines for in vitro and in vivo genetic toxicology testing. Environ $\mathrm{Mol}$ Mutagen. 2000;35(3):206-221.

14. Nadin SB, Vargas-Roig LM, Ciocca DR. A silver staining method for single-cell gel assay. J Histochem Cytochem. 2001;49(9):1183-1186.

15. Konca K, Lankoff A, Banasik A, et al. A cross-platform public domain PC image-analysis program for the comet assay. Mutat Res. $2003 ; 534(1-2): 15-20$ 